\section{Residências Secundárias - As Fontes Estatísticas e a Questão Conceitual}

\section{Olga Tulik}

RESUMO: Análise teórica de residências secundárias como modalidade de alojamento turístico particular utilizado temporariamente nos momentos de lazer, po pessoas que têm domicilio permanente num outro lugar A partir da abordagem do tema na literatura específica, cstabclece-se a relaça entre as fontes estatisticas c a questão conceitual para chegar à compreensão do terme no Brasil.

PALAVRAS-CHAVE: Teoria do turismo; residências secundárias; censos de domicílios; Brasil.

ABSTRACT: This is a theoretical analysis of secondary residences as private tourist housing, used temporaril during leisure time by people who live eisewhere. Trough the approach brought by the specific literature, statistical sources are related with conceptual questions to arrive at the comprehension of the term in Brazil.

KEY WORDS: Theory of tourism; secondary residences domicile census; Brazil.

\section{Introdução}

Fenômeno antigo e universal, a residência secundária se afirma, atualmente, como uma das mais difundidas dentre as diversas modalidades de alojamento turístico.

O estudo das residências secundárias, entretanto, esbarra no problema da obtenção de dados. Nos Estados Unidose em alguns países europeus, as residências

1. Bacharel em Geografia pela Faculdade de Filosofia, Letras e Ciências Humanas da USP. Livre-Docente pela Escola de Comunicaçōes e Artes da USP. Professora Associada do Curso de Turismo e do Mestrado en Turismo e Lazer da ECA.USP.

Prof Lúcio Martins Rodrigues, 443 - Bloco B - 05508-900 - São Paulo - SP - Brasil - Fax: (011) 818-4331. secundárias aparecem incluídas nas estatísticas oficiais, a partir da década de 50 , entre os domicílios fechados, o que ocorreu também, no Brasil, em 1970. Desse fato decorrem as dificuldades dos pesquisadores, pois é evidente que residências secundárias não podem ser confundidas com domicílios fechados.

No Brasil, essa questão se resolveu a partir dos dois últimos censos demográficos realizados, respectivamente, em 1980 c 1991, onde aparece uma de relação destes com as residênciassecundárias fica explícita na definição operacional como será visto no decorrer deste estudo.

\section{Fontes Estatisticas e a Questão Conceiłual}

Residências secundárias constituem parte dos meios de hospedagem. Estes, por sua vez integram a oferta turística que está compreendida nas estruturas e nos processos do desenvolvimento turístico (Pearce, 1988:19).

A distribuição dos meios de hospedagem tem sido amplamente utilizada paramedir as variações espaciais do turismo, pois constituemuma das mais visívei e tangíveis manifestações desta atividade sendo, geralmente, inventariadas com finalidades estatísticas c propósitos fiscais (Pearce, 1987:113). Em vários países, inclusive no Brasil, os Censos Demográficos, especificamente na parte referente aos domicílios, fornecem dados estatísticos sobre as residências secundárias. Incluídas cntre domicílios fechados c vagos, as residências sccundárias podem ser inferidas a partir dos conceitos operacionais formulados pelos órgãos censitários

Oúltimo Censo Demográfico realizado pelo Instituto Brasileiro de Geografia e Estatística, em 1991, classifica os domicílios ${ }^{2} \mathrm{em}$ duas grandes categorias particulares, que englobam os ocupados, fechados, vagos e de uso ocasional; coletivos que compreendem hotéis, pensões, recolhimentos, asilos, orfanatos, conventos, penitenciárias, quartéis, postos militares, navios, alojamentos de trabalhadores etc... (IBGE, 1991:11).

As residências secundárias, objeto desta pesquisa, identificam-se com os domicílios de uso ocasional que são definidos como

... o domicilio particular que servia de moradia (casa ou apartamento), isto é, os usados para descanso de fim-de-semana, férias ou outro fim. (IBGE, 1991:13)

A preocupação com uma categoria específica que tenha o sentido do que se entende por residência secundária é relativamente recente no Brasil. A evolução dos conceitos operacionais do IBGE pode dar uma idéia deste fato.

2. "Domicílio é a mora

(IBGE, 1991:12)

(2)

31 de a investigą̧ão das caracteristicas dos domiciliose das pessoas neles residentes, a data de referência foi a noite de

31 de agosto para 1 ' de setembro". (IBGE, 1991:11) 
O Recenseamento Demográfico de 1970 registra, pcla primeira vez, as residências secundárias que aparecem incluídas entre os domicílios fechados. Era assim considerado o domicílio

que servia ocasionalmente de moradia (casa de praia, ou campo, normalmente usadas para descanso de fim-de-semana ou férias) e cujos moradores não estavam presentes na data do censo. (IBGE, 1970) sendo de

No Recenseamento Demográfico seguinte (1980), aparece designado como

uso ocasional o domicilio que servia ocasionalmente de moradia (casa ou apartamento) normalmente usado para fim-de-semana ou férias, cujos moradores não estavam presentes na data do censo. (IBGE, 1980: IX)

Comparando os conceitos operacionais acima mencionados com o atual correspondente ao censo de 1991, percebe-se que a diferença principal restringese à questão da presença do morador ocasional. Em 1991, porém, a condição de domicílio ocasional foi atribuída mesmo que, "na data de referência do censo, estivessem presentes seus ocupantes" (IBGE, 1991: 24). Entretanto, o aprimoramento maior ocorreu de 1970 para 1980 quando houve uma preocupação do órgão censitário em criar uma categoria específica para este tipo de domicílio, scparandoo dos fechados que, cvidentemente, não podem ser confundidos com residências sccundárias.

Dados estatísticos do Censo Demográfico de 1970 (no qual as residências secundárias estavam incluídas entre os domicílios fechados) foram utilizados por Langenbuch que, numa exaustiva pesquisa, procurou determinar os municípios do Estado de São Paulo que apresentavam, em escala expressiva, a função de recepção turística (Langenbuch, 1977:1-49). Para alcançar o seu objetivo, o mencionado autor elaborou uma avaliação relativa da capacidade de alojamento turístico adaptando a taxa de função turística, proposta por P. Defert, amplamente utilizadi pelos especialistas em turismo, que relaciona o número de leitos turísticos da área considerada com a população local' (Langenbuch, 1977:5). A questão levantada pelo autor, c que mais diretamente está ligada a esta análise, diz respeito à categoria dos domicílios fechados, onde apareciam incluídas as residências secundárias, pois Langenbuch constatou, atravćs de pesquisas de campo que, entre cles, apareciam. também, "residências secundárias de caráter não turistico" (Langenbuch, 1977:89). Deste fato decorria, em alguns casos, uma "falsa taxa de função turística resultante de um grande número de domicílios fechados", com utilização divcrsa do turismo, c que não podiam ser enquadrados como residências secundárias. correspondendo às seguintes situações:

4. Taxa de Função Turistica de P. Defert: $T=\left(n^{0}\right.$ de leitos turisticos $/ n^{\circ}$ de habitantes $) \times 100$
- "cm Jambeiro, Lagoinha, Mira Estrela e Natividade da Serra, casas-sede de sítios, pertencendo aos agricultores que apenas as ocupavam nos domingos c dias de festas religiosas (reminiscências de hábito outrora arraigado no Brasil de Sudeste); cabanas na zona nural ocupadas apenas parte do ano por trabalhadores temporários"(Langenbuch, 1977:11);

- em Porto Ferreira - domicílios fechados, que correspondiam, essencialmente, a ranchos de pesca pertencentes a residentes na própria cidade e desconsiderados pelo autor por não envolver deslocamento de um município para outro (Langenbuch, 1977: 11-2).

Percebc-sc que, na operacionalização dos conccitos do IBGE para 1980 c 1991, esta falha foi sanada pois, conforme já analisado anteriormente, domicílio fechado c de uso ocasional aparecem separadamente. A partir destes censos, portanto, os estudos sobre esta forma de alojamento turíst ico não estão apoiados $\mathrm{cm}$ domicílios fechados (objeto das acertadas restrições de Langenbuch), mas naqueles de uso ocasional, aqui entendidos comosendo residências secundárias, uma vez que o sentido destas está afim com o conceito operacional emitido em relação a cles.

Outro aspecto abordado por Langenbuch (1977:9) refere-se à falta de dados distritais, nurais e urbanos, além de dificuldade para distinguir outras formas de alojamento como colônias de férias, acampamentos etc...

No último Censo Demográfico, foram introduzidos dados estatísticos que permitem superar alguns destes problemas entre cles a situação do domicílio de uso ocasional (urbano c nural) c a especificação dos distritos $\mathrm{cm}$ que se encontram Entretanto, ainda permanecem entre os domicílios coletivos os vários tipos ja mencionados anteriormente, dificultando as pesquisas sobre alojamentos turísticos não particulares. Convém lembrar que, cmbora residências secundárias c hotéis compreendam as modalidades mais difundidas no Brasil (como ocorre no mundo inteiro), cxistem outras que poderiam ser detectadas desde o início pelo recenseamento de domicílios. Apart-hotéis, acampamentos, hotéis de lazer, unidades de tempo compartilhado ("time sharing") e outras poderiam ser melhor analisadas c entendidas quanto às exigências de serviços e de outros equipamentos necessários, e às repercussões espaciais decorrentes de sua procura, se os pesquisadores pudessem contar com os dados estatísticos do IBGE.

Percebe-se a cxtrema complexidade que envolve a questão conceitual e a obtenção de dados estatísticos de meios de alojamento em geral e, especificamente de residências secundárias. Este fato encontra apoio na cxpressão "outro fim" que consta na conccituação do domicílio de uso ocasional do censo de 1991 sugerindo utilização diversa do "descanso de fim-de-scmana c férias". Apesar das lacunas c enganos, que podem atć mesmo cxistir, os dados do IBGE constituem a fonte mais confiável atć agora encontrada sendo, também, o único órgão que dispõe de dados estatísticos para uma análise das residências secundárias no Estado de São Paulo. As dificuldades encontradas no Brasil também ocorrem em outros países. $\mathrm{Na}$ França, por cxemplo, somente a partir de 1954 aparecem dados oficiais sobre 
domicílios fechados que, pelo conceito operacional, foram entendidos como residências secundárias. Alćm disso, mesmo após cste começo, as cstatísticas foran consideradas deficientes, scja por englobar outras formas de alojamento, como os domicílios vagos, seja por subestimar os valores, como aconteceu no Censo de 1968 (Boyer, 1972:124). Infelizmente, informações mais recentes não foram obtidas o que anula qualquer possibilidade de comparação contemporânea. Alćm disso, conforme já foi mencionado, a questão temporal parece ter culminado em momentos diferenciados entre os países, pois o interesse pelas pesquisas de residências sccundárias começa, no Extcrior, cntre 1970 c o final da década de 1980, cnquanto que, no Brasil, o assunto ainda está por merecer estudos aprofundados.

A questão conccitual c a necessária c incvitável busca por uma definiç̧ão são cm parte, reflexos da profusão de termos alternativos, de sentido amplo ou restrito nos mais diversos idiomas, aplicados conforme as modalidades turísticas praticiz das c as especificidades locais: $\mathrm{em}$ português, encontram-se os termos domicílio do uso ocasional (IBGE), residência turística (Langenbuch), residência secundária, segunda residencia e outras formas de uso corrente como casas de campo, de temporada, de praia, de verancio, alćm de chalć, cabana, sítio e chácara de lazer ou de recreio; em francês, "residence secondaire" "maison de campagne", "residence touristique"; cm inglês, "second home", "vacation home"; cm espanhol, "segund casa", "scgundo hogar", "casas vacacionales"; cm italiano, "scconda casa" c outros tantos termos que devem existir para cxpressar aquete que não é o domicílio principal.

Alguns destes termos são muito restritivos, o que limita a sua aplicação genćrica, como, por exemplo, casa de temporada. Este vocábulo específico se aplica ao domicílio utilizado $\mathrm{cm}$ períodos mais longos, a chamada temporada de férias, mas pode, tambćm, ser utilizado cm periodos mais curtos, o fím-de-semana; po outro lado, esta casa de temporada tanto pode ser uma casa de praia como de montanha, ou dec campo. O que se verifica é que, na maioria das vezes, estes termos refletem causas circunstanciais e são influenciados por fatores de ordem cultural

De qualquer modo e qualquer que scja o termo aplicado ao domicilio ou imóvel que serve como residência secundária, csta modalidade de alojamento turístico apresenta aspectos conceituais que merecem ser analisados $\mathrm{e}$ avaliados $\mathrm{cm}$ função da realidade brasilcira.

O Dicionário de Geografia Humana conccitua residência secundárí ("second home") como a propriedade que pode ser própria, alugada ou arrendada por uma família, cuja residência normal cstá situada $\mathrm{cm}$ outro local. Tal propricdade, usualmente situada $\mathrm{em}$ áreas rurais, é utilizada com propósito de recreação Destaca Pcıv, o autor do verbetc, que esta definição não ć aceita de modo satisfatório. em nível internacional, para fins de coleta de dados (Johnston, 1989:302).

Para Ragatz, a residência de férias ("vacation home") compreende un domicílio familiar, sendo que os ocupantes devem ter algum outro lugar como residência principal. Destaca, ainda, que a residência de férias deve ter sido construida, originalmente, com o propósito de realizar atividades no tempo de lazer (Ragatz, 1970:447).
Analisando o caso da França, Boyer (1972:124) mostra que cxiste uma dificuldade de definição, pois no sentido corrente, o termo corresponde a uma residência de lazer que o proprietário, habitualmente morador em área urbana, utiliza para passar férias, total ou parcialmente, c para os fins-de-semana. Segun utiliza pator, em 1962, o censo realizado na França qualificou como residências cste autor, "“residences secondaires") as casas c os apartamentos mobiliados, secundárias ("residences secondaires") as casas c os apartamentos mobiliados, a defiluição de 1969, entretanto, compreende tanto as residências secundárias própridefiıtição de rio pode dispor a qualquer momento (Sécretariat d'Etat au Tourisme, 1977:127)

Relacionando a residência secundária ao turismo sedentário, Sanchez (1985:111) observa que tal modalidade de alojamento tu

repetido do mesmo espaço, criando alguma forma de vínculo terrıtorial c psıcosociológico. Este vínculo, definido pela intenção de uso, e

espacial restrita a períodos ocasionais menores ou semi-permanentes c mais duradouros.

Considerando as diversas conceituações, alguns aspectos merecem ser avaliados em virtude das grandes diferenças observadas entre clas, muitas das quais só podem ser cxplicadas por fatores como a localização geográfica e o contexto cultural.

Uma primeira questão diz respeitoà propricdade ou não do imóvel que serve como residência secundária. O fato de se tratar de domicílio particular, no conceito operacional do IBGE, já confere à residência secundária o sentido de propricdade, embora ela possa ser alugada ou arrendada. É o que se percebe, também em Peiv (apud Johnston, 1985:302), cm Boyer (1972:124) c na definição do órgão oficial de turismo da França (Sćcretariat d'Etat au Tourisme, 1977:127). Sanchez (1985:111) vai além cstabclecendo a relação com um vínculo territorial c psicosociológico. A questão de propricdade, entretanto, ć omitida no estudo de Ragatz (1970:447).

Conclui-se, portanto, que a residência secundária, enquanto propriedade particular (já que não existem, pelo menos no Brasil, residências secundárias públicas), constitui uma modalidade de alojamentoturísticocujo conceito operacional não deveria estar ligado ao fato de ser própria, alugada, arrendada ou emprestada.

A questão prática referente à propriedade da residência secundária torna-se mais complexa quando se verifica que muitos moradores alugam suas residências permanentes para turistas que, temporariamente, se transferem para a casa de parentes c amigos, almejando, desta forma, obter uma renda adicional.

No caso brasilciro, em virtude desta complexidade, impossível de ser analisada em qualquer estudo amplosobrecste fenômeno, sugere-se a utilização dos dados estatísticos do Censo Demográfico, considerando-a residência secundária enquanto domicílio, excluindo-se a sua condição de propriedade.

Quanto à localização $\mathrm{em}$ zona urbana ou rural, observam-se duas condições: omissão do fato (IBGE c Sanchez); possibilidade de vínculo territorial nural ou urbano (Pew, c indirctamentc, Boyer). 
Acredita-sc que, cm certas áreas, o contcxto cultural possa cxplicar esia questão. Nas áreas de ocupação antiga, por cxemplo da França, verificou-se que a maioria das residências secundárias provém de heranças ou da aquisição de casas rurais desocupadas (Boyer, 1972:119) c que a busca pelo campo c pela natureza constitui uma aspiração antiga desses habitantes. $\mathrm{O}$ mesmo não acontece $\mathrm{cm}$ outras áreas de ocupação recente, que dispõcm de espaços vazios. Nestes casos, o processo de loteamento ocorre num ritmo acclerado, desencadcando a chamada especulação imobiliária que, além de repercussões negativas, $t \mathrm{~cm}$ contribuido para urbanizar as destinações. Percebe-se que a localização da residência secundária, na área urbana ou rural, ć uma questão irrelevante no quc diz respeito ao conceito operacional c pode, $\mathrm{cm}$ certos casos, ser explicada por fatores circunstanciais c ou culturais.

Especificar na conceituação que o imóvel deve ter sido construído para ser uma residência sccundária constitui, sem dúvida, uma questão, no mínimo, interessante. Evidentemente, muitas residências secundárias foram construídas com o propósito de serem utilizadas no tempo livre. Esta intenção era comum cm 1967, na França, com um quinto das residências secundárias (Boyer, 1972:119). O mesmo acontece em outros lugares, inclusive no Brasil, onde a maioria das residências secundárias é construída para tal fim. O propósito inicial de uso cxclusivo para residência secundária aparece claramente, no trabalho de Ragat\% (1970:447). Todavia, observa-sc que, na prática, nem sempre isto acontece. Muitas vezes, as residências secundárias só se definem como tal, após terem servido como residências permanentes. Em outros casos, é a residência secundária que se torna a principal. É indiscutivel, porém, que enquanto alojamento turístico elas são utilizadas no tempo livre, seja cle de férias ou de fim-de-semana, prolongado ou não, e que seu uso cstá condicionado à recreação $\mathrm{c}$ ao lazer

Existem certas concordâncias entre os autores que, também, podem ser observadas empiricamentc. Por exemplo, a idéia de residência sccundária contrapõe-se à de residência permanente, também denominada principal, normal ou primária. Isto significa que o ocupante da residência secundária deve, obrigatoriamente, habitar um outro domicilio, considerado principal. Desta forma, percebese um dos componentes básicos do turismo - o deslocamento por mais de 24 horas, cnvolvendo pernoitc, razão principal da necessidade de um alojamento turístico no tempo livre. A propósito desta questão, Michaud (1985:93) observa que convén falar de alojamento turístico, não de lazer, e que por definição, os alojamentos recebem pessoas em deslocamento, por mais de 24 horas, ainda que o motivo seja lazer, saúde, negócios etc.

A temporalidade na ocupação corresponde a uma outra concordância cntre os autores. Ningućm reside, permanente, numa residência secundária, mas ocupa csse espaço por periodos mais ou menos prolongados em função do tempo livre. di disponibilidade financeira $\mathrm{c}$ da distância do domicílio principal. Estes c outros fatores contribuem para explicar as concentrações de residências secundárias cm certas árcas.

Residência secundária, portanto, opõc-sc à residência principal e, enquanto madidade de alojamento turístico para fins de recreação e lazer, sua utilização compreende o uso temporário por períodos que podem ser prolongados ou não. Alguns autores observam que o uso pode ser repetido, mas não consecutivo por Alguns autorior a um ano, cstabelecendo o já mencionado vínculo territorial e um periodo sulelismo com a definição aceita para turista, fato que reforça a noção da certo paralelismo ćria como alojamento turístico. Residência secundária, portanto, residência secundaria como alojamento turístico. Residência secundaria, portanto, é um alojamento turistico particular, utilizado temporariamente nos

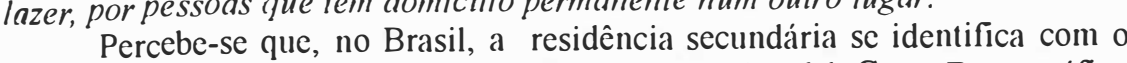
domicílio de uso ocasional, conforme a defínição operacional do Censo Demográfico do IBGE (1991).

Explica-sc a utilização do termo residência secundária ou segunda residência, por tratar-se de vocábulos já consagrados pclo uso na literatura específica de turismo e que, sendo genéricos, podem ser aplicados às mais diversas situações.

\section{Consideraçōes Finais}

A abordagem das fontes estatísticas $\mathrm{c}$ da questão conceitual relacionada às residências secundárias constitui apenas um aspecto na análise dessc fenômeno, que no mundo contemporâneo vem assumindo importância crescente. Existem outras questões que merecem estudos cuidadosos como, por exemplo, as repercussões espaciais c socioculturais que vêm sendo registradas no mundo inteiro, entre as quais se destacam a especulação imobiliária, alteração dos recursos naturai básicos, instalação de residências secundárias em solos com vocação agrícola c influência de turistas residentes nas comunidades $\mathrm{cm}$ função de sua força política e econômica.

No Brasil, o desenvolvimento do turismo sedentário associado às residências secundárias merece atenção, principalmentc quanto à tendência da municipalização, o que cxigc o conhecimento de dados estatísticos para a mensuração desse fenômeno e a sua avaliação como componente importante, mas não único, na captação de recursos financciros.

No que diz respcito à utilização das fontes cstatísticas, convém considerar não apenas os números absolutos, mas também, os valores relativos que mostram a realidade das residências secundárias no panoramalocal. A questãoda escala relativa torna-se significativa se for considerado que os cfeitos serão muito mais sensíveis nas comunidades menos populosas. Da mesma forma, a distribuição por situação da residência secundária nas áreas urbana c rural deverá ser considerada quando da aprovação de qualquer projeto de loteamento que possa estar dirigido aos turistas.

Deve-se considerar, ainda, que valores médios nem sempre traduzem a realidade e que mesmo os números absolutos devem ser avaliados para identificar pressões diversificadas de residências secundárias num determinado espaço.

Concluindo, torna-se necessário avaliar os dados estatísticos e a questão conceitual, não somente cm virtude da presença, dimensão e expressividade desse 
fenômeno, mas também, como elementos valiosos na elaboração de diretrizes para o desenvolvimento do turismo sedentário apoiado em residências secundárias.

\section{BIBLIOGRAFIA}

BOYER, Marc. Le Tourisme. 1972. Paris: Éditions du Seuil. 261 p.

IBGE. Fundação Instituto Brasileiro de Geografia e Estatística. 1991. Sinopse preliminar do censo demográfico - 1991. São Paulo. Rio de Janeiro. n.19.

IBGE. Fundação Instituto Brasileiro de Geografia e Estatistica. 1981. Sinopse preliminar do censo demográfico. IX' recenseamento geral do Brasil - 1980. São Paulo. Rio de Janeiro. v.1. Tomo 1, n.18.

IBGE. Fundação Instituto Brasileiro de Geografia e Estatistica. 1991. Censo Demográfico - 1991. Resultados do universo relativos às caracteristicas da população e dos domicilios. São Paulo. Rio de Janeiro. n.21. p.1.764.

JOHNSTON, R.J. (ed.). 1985. Dictionary of human geography. New York: The Free Press.

LANGENBUCH, Juergen R. 1977. Os municipios turisticos do Estado de São Paulo. Determinação e caracterização geral. São Paulo. Geografia. v.2, n.3, abr., p.1-49

MICHAUD, Jean Luc. 1985. Le tourisme face à l'environnement. France:PUF, 235p.

PEARCE, Douglas. 1987. Tourist development. London: Longman.

PEARCE, Douglas. 1988. Tourism loday. A geographical analysis. London: Longman. 227p.

RAGATZ, Richard Lee. 1970. Vacation homes in the Northeastem United States. Seasonality in population distribution Annals of Association of Geographers. v. 60, p.447-55.

SANCHEZ, Joan-Eugeni. 1985. Por unageografia del turismo de litoral. Una aproximación metodologica. Madrid. Estudios Territoriales. n. 17 p. 103-22.

SECRETARIAT d'Etatau Tourism. 1977. Lemoniteurdestravaux publicset dubatiment. Aménagementetégquipementes pour le tourisme et les loisirs. 2e. édition. dec. $391 \mathrm{p}$. 